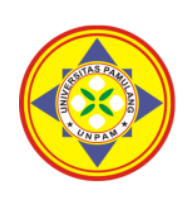

\title{
PENGARUH GAYA KEPEMIMPINAN DAN DISIPLIN KERJA TERHADAP KINERJA PEGAWAI PADA KEMENTERIAN PARIWISATA JAKARTA PUSAT
}

\author{
${ }^{1 *}$ Indra Januar Rukmana, ${ }^{2}$ Mulyadi, ${ }^{3}$ I Nyoman Marayasa \\ Universitas Pamulang, Tangerang Selatan, Banten, Indonesia \\ *dosen02585@unpam.ac.id
}

\begin{abstract}
Abstrak
Penelitian ini bertujuan untuk mengetahui pengaruh gaya kepemimpinan dan disiplin kerja terhadap kinerja pegawai pada Kementerian Pariwisata Jakarta Pusat. Metode yang digunakan adalah explanatory research dengan teknik analisis menggunakan analisis statistik dengan pengujian regresi, korelasi, determinasi dan uji hipotesis. Hasil penelitian ini gaya kepemimpinan berpengaruh signifikan terhadap kinerja pegawai sebesar 54,3\%, uji hipotesis diperoleh $\mathrm{t}$ hitung $>\mathrm{t}$ tabel atau $(7,554>2,011)$. Disiplin kerja berpengaruh signifikan terhadap kinerja pegawai sebesar $41,1 \%$, uji hipotesis diperoleh $\mathrm{t}$ hitung $>\mathrm{t}$ tabel atau $(5,787>2,011)$. Gaya kepemimpinan dan disiplin kerja secara simultan berpengaruh signifikan terhadap kinerja pegawai dengan persamaan regresi $Y=7,707+0,463 X 1+$ $0,347 \mathrm{X} 2$ dan kontribusi pengaruh sebesar $62,6 \%$, uji hipotesis diperoleh $\mathrm{F}$ hitung $>\mathrm{F}$ tabel atau $(39,385$ $>2,800)$.
\end{abstract}

Kata Kunci: Gaya Kepemimpinan, Disiplin Kerja, Kinerja Pegawai

\section{Abstract}

This study aims to determine the effect of leadership style and work discipline on employee performance at the Ministry of Tourism of Central Jakarta. The method used is explanatory research with analytical techniques using statistical analysis with regression, correlation, determination and hypothesis testing. The results of this study that leadership style has a significant effect on employee performance by $54.3 \%$, hypothesis testing is obtained $t$ count $>t$ table or $(7.554>2.011)$. Work discipline has a significant effect on employee performance by $41.1 \%$, hypothesis testing is obtained $t$ count $>t$ table or $(5.787>2.011)$. Leadership style and work discipline simultaneously have a significant effect on employee performance with the regression equation $Y=7,707+$ $0,463 X 1+0,347 X 2$ and the contribution of influence is $62.6 \%$, hypothesis testing is obtained F count $>F$ table or $(39,385>2,800)$.

Keywords: Leadership Style, Work Discipline, Employee Performance.

\section{PENDAHULUAN}

Peranan sumber daya manusia di suatu organisasi sangat penting guna menunjang tercapainya tujuan yang diharapkan. Untuk mencapai tujuan dari perusahaan tersebut, maka seorang pemimpin harus menerapkan gaya kepemimpinan untuk mengelola bawahannya, karena seorang pemimpin akan sangat mempengaruhi keberhasilan organisasi dalam mencapai tujuannya. Menurut Rivai (2016:42) berpendapat bahwa "Gaya kepemimpinan adalah sekumpulan ciri yang digunakan pimpinan untuk memengaruhi bawahan agar sasaran organisasi tercapai atau dapat pula dikatakan bahwa gaya kepemimpinan adalah pola perilaku dan strategi yang disukai dan sering diterapkan oleh seorang pemimpin".

Kementerian Pariwisata Republik Indonesia atau disingkat Kemenpar RI adalah kementerian dalam Pemerintah Indonesia yang membidangi urusan kepariwisataan. Gaya kepemimpinan di Kementerian Pariwisata yang masih bersifat otoriter yang dirasa masih kurang tepat dengan situasi dan kondisi perusahaan sehingga membuat pegawai merasa tidak nyaman dalam melakukan pekerjaannya. Selain itu, ditemenukan beberapa masalah terkait kepemimpian. Masalah-masalah 
yang ditemukan berkaitan dengan gaya kepemimpinan seperti hubungan atasan dengan pegawai yang kurang harmonis serta belum optimalnya partisipasi pemimpin dalam membantu menyelesaikan masalah-masalah yang ada pada organisasi dan pemimpin kurang mampu memberikan motivasi kepada para pegawai.

Tidak hanya gaya kepemimpinan yang mempengaruhi menurunnya kinerja pegawai, disiplin kerja juga dapat mempengaruhi penurunan kinerja pegawai. Kedisiplinan merupakan suatu hal yang menjadi tolak ukur untuk mengetahui apakah peran pimpinan secara keseluruhan dapat dilaksanakan dengan baik atau tidak. Menurut Singodimedjo dalam Sutrisno (2016:86), menyatakan bahwa "Disiplin adalah sikap kesediaan dan kerelaan seseorang untuk mematuhi dan menaati norma-norma peraturan yang berlaku disekitarnya."

Berdasarkan hasil observasi yang dilakukan penulis pada Kementerian Pariwisata Jakarta Pusat, terdapat beberapa pegawai yang sering tidak hadir ke kantor. Data tersebut dapat dihasilkan dari Tabel 1. yang merupakan Tabel absensi pegawai Kementerian Pariwisata.

Tabel 1. Data Absensi Pegawai Kementerian Pariwisata Tahun 2016-2020

\begin{tabular}{|c|c|c|c|c|c|}
\hline \multirow{2}{*}{ Tahun } & \multirow{2}{*}{$\begin{array}{c}\text { Jumlah } \\
\text { Pegawai }\end{array}$} & \multicolumn{3}{|c|}{ Kondisi Absensi } & \multirow{2}{*}{ Jumlah } \\
\cline { 3 - 5 } & TK & Izin & Terlambat & Absensi \\
\hline 2016 & 50 & 15 & 9 & 25 & 49 \\
\hline 2017 & 50 & 20 & 7 & 10 & 37 \\
\hline 2018 & 50 & 8 & 10 & 15 & 33 \\
\hline 2019 & 50 & 30 & 20 & 35 & 85 \\
\hline 2020 & 50 & 24 & 31 & 12 & 67 \\
\hline
\end{tabular}

Sumber: Kementerian Pariwisata Jakarta Pusat, 2020

Keterangan: TK = Tanpa Keterangan

Berdasarkan data pada tabel di atas, menunjukkan absensi kehadiran pegawai selama 5 tahun dari tahun 2016 sampai dengan tahun 2020 yang terlambat dan pegawai yang tidak hadir tanpa keterangan mengalami peningkatan terjadi pada tahun 2019. Maka dilihat dari data absensi di atas dapat disimpulkan bahwa masih kurangnya tingkat disiplin pegawai Kementerian Pariwisata terhadap absensi kehadiran, karena masih terlihat pegawai yang tidak masuk berkerja tanpa memberikan keterangan kepada organisasi.

Agar aktivitas manajemen berjalan dengan baik, perusahaan harus memiliki pegawai yang berpengetahuan dan berketrampilan tinggi serta usaha untuk mengelola perusahaan seoptimal mungkin sehingga kinerja pegawai meningkat. Kinerja yang baik adalah kinerja yang optimal, yaitu kinerja yang sesuai standar organisasi dan mendukung tercapainya tujuan organisasi. Dalam lingkungan Kementerian Pariwisata, dimana kurangnya informasi dan sosialisasi terhadap ketentuan dan peraturan sehingga seringkali terjadi kesimpangsiuran dalam penyelesaian pekerjaan yang diinstruksikan oleh pimpinan.

Selanjutnya berdasarkan penilaian kinerja pegawai Kementerian Pariwisata dari tahun 2016-2020 dengan jumlah pegawai 50 orang, dapat dilihat pada tabel dibawah ini :

Tabel 2. Data Kinerja Pegawai Kementrian Pariwisata Tahun 2016-2020

\begin{tabular}{|c|c|c|c|c|c|c|c|c|c|}
\hline \multirow{3}{*}{ Tahun } & \multicolumn{3}{|c|}{$\begin{array}{c}\text { Meningkatkan } \\
\text { Kontribusi } \\
\text { Kepariwisataan } \\
\text { terhadap Produk } \\
\text { Domestik Bruto }\end{array}$} & \multicolumn{3}{c|}{$\begin{array}{c}\text { Meningkatkan unit } \\
\text { usaha sektor } \\
\text { ekonomi kreatif }\end{array}$} & $\begin{array}{c}\text { Meningkatkan } \\
\text { kualitas dan } \\
\text { kuantitas lulusan } \\
\text { pendidikan tinggi } \\
\text { pariwisata }\end{array}$ \\
\cline { 2 - 11 } & TG & RL & $\%$ & TG & RL & $\%$ & TG & RL & $\%$ \\
\hline 2016 & 4 & 4,23 & 105,7 & 7,2 & 10,59 & 147,1 & 1490 & 1685 & 113,1 \\
\hline 2017 & 4,2 & 4,01 & 95,4 & 7,31 & 9,68 & 132,4 & 1900 & 2100 & 110,5 \\
\hline 2018 & 4,2 & 3,88 & 92,4 & 8 & 10.5 & 131,2 & 1443 & 1437 & 99,6 \\
\hline
\end{tabular}




\begin{tabular}{|l|l|l|l|l|l|l|l|l|l|}
\hline 2019 & 5 & 4,13 & 82,6 & 8 & 7,52 & 94,0 & 1800 & 1786 & 99,2 \\
\hline 2020 & 5 & 4,03 & 80,6 & 10 & 8,75 & 87,5 & 1500 & 1430 & 95,3 \\
\hline
\end{tabular}

Sumber: Kementerian Pariwisata Jakarta Pusat, 2020

Berdasarkan tabel diatas 2. diatas dapat dilihat tingkat kinerja pegawai Kementerian Pariwisata dalam kegiatan untuk meningkatkan kontribusi kepariwisataan terhadap produk domestik bruto, meningkatkan unit usaha sektor ekonomi kreatif, dan kegiatan untuk meningkatkan kualitas dan kuantitas lulusan pendidikan tinggi pariwisata dari tahun 2016 sampai dengan tahun 2020 mengalami penurunan.

Kinerja
penurunan
karena $\begin{array}{r}\text { mengalami } \\ \text { faktor-faktor }\end{array}$
diantaranya gaya kepemimpinan yang belum memenuhi standar sehingga kinerja belum optimal. Adapun gejala-gejala yang timbul dari kurangnya bimbingan yang diberikan pimpinan sehingga banyak pegawai yang datang terlambat dan banyaknya pekerjaan yang tertunda yang mengakibatkan pekerjaan yang tidak terselesaikan tepat pada waktu yang telah ditentukan oleh organisasi.

Kinerja Pegawai yang tinggi sangatlah diharapkan oleh setiap perusahaan. Menurut Anwar Prabu Mangkunegara (2013:67) berpendapat bahwa "Kinerja adalah hasil kerja secara kualitas dan kuantitas yang dicapai oleh seseorang pegawai dalam melaksanakan tugasnya sesuai dengan tanggung jawab yang diberikan kepadanya".

Berdasarkan permasalahan tersebut, peneliti mengajukan sebuah penelitian dengan judul "Pengaruh Gaya kepemimpinan Dan Disiplin Kerja Terhadap Kinerja Pegawai Pada Kementerian Pariwisata Jakarta Pusat".

\section{TINJAUAN PUSTAKA}

\section{Gaya kepemimpinan}

Menurut Rivai (2014:42)
menyatakan bahwa
"Gaya
yang digunakan pimpinan untuk
memengaruhi bawahan agar sasaran
organisasi tercapai atau dapat pula
dikatakan bahwa gaya kepemimpinan

adalah pola perilaku dan strategi yang disukai dan sering diterapkan oleh seorang pemimpin". Adapun indikator yang dapat digunakan meliputi: Otokratik, Kharismatik, Demokratik, Militeristik, Laissez-faire.

2. Disiplin kerja

Menurut Edy Sutrisno (2016:89) “Disiplin adalah perilaku seseorang yang sesuai dengan peraturan, prosedur kerja yang ada atau disiplin adalah sikap, tingkah laku, dan perbuatan yang sesuai dengan peraturan dari organisasi baik tertulis maupun tidak tertulis". Adapun indikator yang dapat digunakan meliputi: Taat terhadap aturan waktu, Taat terhadap peraturan perusahaan, Taat terhadap aturan perilaku perusahaan, Taat terhadap peraturan lainnya.

\section{Kinerja Pegawai}

Dalam penelitian ini yang dijadikan variabel dependen adalah kinerja pegawai yang diartikan sebagai "Kinerja Pegawai adalah hasil kerja secara kualitas dan kuantitas yang dicapai oleh seseorang pegawai dalam melaksanakan tugasnya sesuai dengan tanggung jawab yang diberikan kepadanya", Menurut Anwar Prabu Mangkunegara (2014:9). Adapun indikator yang dapat digunakan meliputi: Kualitas Kerja, Kuantitas Kerja, Tanggung Jawab, Kerjasama, Inisiatif.

\section{METODE}

Populasi dalam penelitian ini berjumlah 50 responden Kementerian Pariwisata Jakarta Pusat, sampel dalam penelitian ini berjumlah 50 responden, jenis penelitian yang dipakai adalah kuantitatif, dimana tujuannya adalah untuk mengetahui pengaruh antara variabel bebas terhadap variabel terikat baik parsial maupun simultan. Dalam menganalisis data digunakan uji instrumen, uji asumsi klasik, regresi, koefisien korelasi, koefisien determinasi dan uji hipotesis. 
HASIL DAN PEMBAHASAN

\section{Analisis Deskriptif}

Pada pengujian ini digunakan untuk mengetahui skor minimum dan maksimum, mean score dan standar deviasi dari masing-masing variabel. Adapun hasilnya sebagai berikut:

Tabel 3. Hasil Analisis Descriptive Statistics

Descriptive Statistics

\begin{tabular}{lr|r|r|r|r} 
& N & Minimum & Maximum & Mean & Std. Deviation \\
\hline Gaya kepemimpinan (X1) & 50 & 31 & 48 & 37.30 & 4.376 \\
\hline Disiplin Kerja (X2) & 50 & 29 & 48 & 37.60 & 3.648 \\
\hline Kinerja Pegawai (Y) & 50 & 32 & 48 & 38.04 & 3.681 \\
\hline Valid N (listwise) & 50 & & & & \\
\hline
\end{tabular}

Gaya kepemimpinan diperoleh varians minimum sebesar 31 dan varians maximum 48 dengan mean score sebesar 37,30 dengan standar deviasi 4,376.

Disiplin kerja diperoleh varians minimum sebesar 29 dan varians maximum 48 dengan mean score sebesar 37,60 dengan standar deviasi 3,648.

Kinerja pegawai diperoleh varians minimum sebesar 32 dan varians maximum 48 dengan mean score sebesar 38,04 dengan standar deviasi 3,681.

\section{Analisis Verifikatif}

Pada analisis ini dimaksudkan untuk mengetahui pengaruh variabel independen terhadap variabel dependen. Adapun hasil pengujian sebagai berikut:

\section{a. Analisis Regresi Linier Berganda}

Uji regresi ini dimaksudkan untuk mengetahui perubahan variabel dependen jika variabel independen mengalami perubahan. Adapun hasil pengujiannya sebagai berikut:

Tabel 4. Hasil Pengujian Regresi Linier Berganda Coefficients ${ }^{a}$

Unstandardized Coefficients

\begin{tabular}{l|r|r|r|r|r}
\multicolumn{1}{l}{ Model } & \multicolumn{1}{c|}{ B } & Std. Error & Beta & \multicolumn{1}{c}{$\mathrm{t}$} & \multicolumn{1}{c}{ Sig. } \\
\hline 1 (Constant) & 7.707 & 3.590 & & 2.147 & .037 \\
\hline Gaya kepemimpinan (X1) & .463 & .089 & .551 & 5.204 & .000 \\
\hline Disiplin Kerja (X2) & .347 & .107 & .344 & 3.247 & .002 \\
\hline
\end{tabular}

a. Dependent Variable: Kinerja Pegawai $(Y)$

Berdasarkan hasil pengujian pada tabel di atas, diperoleh persamaan regresi $Y=7,707+0,463 X 1$ $+0,347 X 2$. Dari persamaan tersebut dijelaskan sebagai berikut:

1) Konstanta sebesar 7,707 diartikan jika gaya kepemimpinan dan disiplin kerja tidak ada, maka telah terdapat nilai kinerja pegawai sebesar 7,707 point.

2) Koefisien regresi gaya kepemimpinan sebesar 0,463, angka ini positif artinya setiap ada peningkatan gaya kepemimpinan sebesar 0,463 maka kinerja pegawai juga akan mengalami peningkatan sebesar 0,463 point.
3) Koefisien regresi disiplin kerja sebesar 0,347, angka ini positif artinya setiap ada peningkatan disiplin kerja sebesar 0,347 maka kinerja pegawai juga akan mengalami peningkatan sebesar 0,347 point.

\section{b. Analisis Koefisien Korelasi}

Analisis koefisien korelasi dimaksudkan untuk mengetahui tingkt kekuatan hubungan dari variabel independen terhadap variabel dependen baik secara parsial maupun simultan. Adapun hasil pengujian sebagai berikut: 
Tabel 5. Hasil Pengujian Koefisien Korelasi Gaya kepemimpinan Terhadap Kinerja Pegawai.

\section{Correlations $^{b}$}

\begin{tabular}{|c|c|c|c|}
\hline & & $\begin{array}{c}\text { Gaya } \\
\text { kepemimpinan } \\
(\mathrm{X} 1)\end{array}$ & $\begin{array}{c}\text { Kinerja Pegawai } \\
(\mathrm{Y})\end{array}$ \\
\hline \multirow[t]{2}{*}{$\begin{array}{l}\text { Gaya kepemimpinan } \\
\text { (X1) }\end{array}$} & $\begin{array}{l}\text { Pearson } \\
\text { Correlation }\end{array}$ & 1 & $.737^{*}$ \\
\hline & Sig. (2-tailed) & & .000 \\
\hline \multirow[t]{2}{*}{ Kinerja Pegawai $(Y)$} & $\begin{array}{l}\text { Pearson } \\
\text { Correlation }\end{array}$ & $.737^{* *}$ & 1 \\
\hline & Sig. (2-tailed) & .000 & \\
\hline
\end{tabular}

**. Correlation is significant at the 0.01 level (2-tailed).

b. Listwise $\mathrm{N}=50$

Berdasarkan hasil pengujian diperoleh nilai korelasi sebesar 0,737 artinya gaya kepemimpinan memiliki hubungan yang kuat terhadap kinerja pegawai.

Tabel 6. Hasil Pengujian Koefisien Korelasi Disiplin kerja Terhadap Kinerja Pegawai.

Correlations $^{\mathrm{b}}$ Disiplin Kerja $\quad$ Kinerja Pegawai

\begin{tabular}{|c|c|c|c|}
\hline & & & $(\mathrm{Y})$ \\
\hline \multirow[t]{2}{*}{ Disiplin Kerja (X2) } & Pearson Correlation & 1 & $.641^{* *}$ \\
\hline & Sig. (2-tailed) & & .000 \\
\hline \multirow[t]{2}{*}{ Kinerja Pegawai $(\mathrm{Y})$} & Pearson Correlation & $.641^{* *}$ & 1 \\
\hline & Sig. (2-tailed) & .000 & \\
\hline
\end{tabular}

Berdasarkan hasil pengujian diperoleh nilai korelasi sebesar 0,641 artinya disiplin kerja memiliki hubungan yang kuat terhadap kinerja pegawai.

Tabel 7. Hasil Pengujian Koefisien Korelasi Gaya kepemimpinan dan Disiplin kerja secara simultan Terhadap Kinerja Pegawai.

Model Summary

\begin{tabular}{|c|c|c|c|c|}
\hline \multirow[b]{2}{*}{ Model } & \multicolumn{4}{|c|}{ IIIATy } \\
\hline & $\mathrm{R}$ & R Square & $\begin{array}{l}\text { Adjusted R } \\
\text { Square }\end{array}$ & $\begin{array}{l}\text { Std. Error of the } \\
\text { Estimate }\end{array}$ \\
\hline 1 & $.791^{\mathrm{a}}$ & .626 & .610 & 2.298 \\
\hline
\end{tabular}

Berdasarkan hasil pengujian diperoleh nilai korelasi sebesar 0,791 artinya gaya kepemimpinan dan disiplin kerja secara simultan memiliki hubungan yang kuat terhadap kinerja pegawai.

\section{c. Analisis Koefisien Determinasi}

Analisis koefisien determinasi dimaksudkan untuk mengetahui besarnya persentase pengaruh dari variabel independen terhadap variabel dependen baik secara parsial maupun simultan. Adapun hasil pengujian sebagai berikut:

Tabel 8. Hasil Pengujian Koefisien Determinasi Gaya kepemimpinan Terhadap Kinerja Pegawai.

Model Summary

\begin{tabular}{lr|r|r|rr} 
& & \multicolumn{2}{c}{ Model Summary } & \multicolumn{2}{c}{ Std. Error of the } \\
Model & $\mathrm{R}$ & R Square & $\begin{array}{c}\text { Adjusted R } \\
\text { Square }\end{array}$ & \multicolumn{2}{c}{ Estimate } \\
\hline 1 & $.737^{a}$ & .543 & .533 & 2.516 \\
\hline
\end{tabular}


a. Predictors: (Constant), Gaya kepemimpinan (X1)

Berdasarkan hasil pengujian memiliki kontribusi pengaruh sebesar diperoleh nilai determinasi sebesar $54,3 \%$ terhadap kinerja pegawai.

0,543 artinya gaya kepemimpinan

Tabel 9. Hasil Pengujian Koefisien Determinasi Disiplin kerja Terhadap Kinerja Pegawai.

\section{Model Summary}

\begin{tabular}{l|r|rr|rr} 
& & \multicolumn{2}{|c|}{$\begin{array}{c}\text { Adjusted R } \\
\text { Square }\end{array}$} & \multicolumn{2}{c}{$\begin{array}{c}\text { Std. Error of the } \\
\text { Estimate }\end{array}$} \\
\hline 1 & $\mathrm{R}$ & R Square & Square & .399 & 2.854 \\
\hline
\end{tabular}

a. Predictors: (Constant), Disiplin Kerja (X2)

Berdasarkan hasil pengujian diperoleh nilai determinasi sebesar

kontribusi pengaruh sebesar $41,1 \%$ 0,411 artinya disiplin kerja memiliki terhadap kinerja pegawai.

Tabel 10. Hasil Pengujian Koefisien Determinasi Gaya kepemimpinan dan Disiplin kerja Terhadap Kinerja Pegawai.

Model Summary

\begin{tabular}{l|c|c|cr} 
Model & $\mathrm{R}$ & R Square & $\begin{array}{c}\text { Adjusted R } \\
\text { Square }\end{array}$ & \multicolumn{2}{c}{$\begin{array}{c}\text { Std. Error of the } \\
\text { Estimate }\end{array}$} \\
\hline 1 & $.791^{\mathrm{a}}$ & .626 & .610 & 2.298 \\
\hline a. Predictors: (Constant), Disiplin Kerja (X2), Gaya kepemimpinan (X1)
\end{tabular}

Berdasarkan hasil pengujian diperoleh nilai determinasi sebesar 0,626 artinya gaya kepemimpinan dan disiplin kerja secara simultan memiliki kontribusi pengaruh sebesar $62,6 \%$ terhadap kinerja pegawai, sedangkan sisanya sebesar $37,6 \%$ dipengaruhi faktor lain. d. Uji Hipotesis

Uji hipotesis Parsial (Uji t)

Pengujian hipotesis dengan uji $t$ digunakan untuk mengetahui hipotesis parsial mana yang diterima.

Hipotesis pertama: Terdapat pengaruh yang signifikan antara gaya kepemimpinan terhadap kinerja pegawai.

Tabel 11. Hasil Uji Hipotesis Gaya kepemimpinan Terhadap Kinerja Pegawai.

\section{Coefficients $^{\mathrm{a}}$}

\begin{tabular}{|c|c|c|c|c|c|}
\hline \multirow[b]{2}{*}{ Model } & \multicolumn{2}{|c|}{$\begin{array}{l}\text { Unstandardized } \\
\text { Coefficients }\end{array}$} & \multirow{2}{*}{$\begin{array}{c}\text { Standardize } \\
\mathrm{d} \\
\text { Coefficients } \\
\text { Beta }\end{array}$} & \multirow[b]{2}{*}{$\mathrm{t}$} & \multirow[b]{2}{*}{ Sig. } \\
\hline & B & Std. Error & & & \\
\hline 1 (Constant) & 14.933 & 3.083 & & 4.843 & .000 \\
\hline $\begin{array}{l}\text { Gaya kepemimpinan } \\
\text { (X1) }\end{array}$ & .619 & .082 & .737 & 7.544 & .000 \\
\hline
\end{tabular}

a. Dependent Variable: Kinerja Pegawai $(\mathrm{Y})$

Berdasarkan hasil pengujian pada tabel di atas, diperoleh nilai $\mathrm{t}$ hitung $>\mathrm{t}$ tabel atau $(7,554>2,011)$, dengan demikian hipotesis pertama yang diajukan bahwa terdapat pengaruh yang signifikan atara gaya kepemimpinan terhadap kinerja pegawai diterima.

Tabel 12. Hasil Uji Hipotesis Disiplin kerja Terhadap Kinerja Pegawai.

\section{Coefficients $^{\mathrm{a}}$}

Unstandardized

Coefficients

\begin{tabular}{lr|r|c|c|c}
\multicolumn{1}{c|}{ Model } & B & Std. Error & Beta & $\mathrm{t}$ & Sig. \\
\hline $1 \quad$ (Constant) & 13.715 & 4.222 & & 3.248 & .002 \\
\hline
\end{tabular}




\begin{tabular}{ll|l|l|l|l|l}
\hline Disiplin Kerja $(\mathrm{X} 2)$ & .647 & .112 & .641 & 5.787 & .000 \\
\hline
\end{tabular}

a. Dependent Variable: Kinerja Pegawai (Y)

Berdasarkan hasil pengujian pada tabel di atas, diperoleh nilai $t$ hitung $>\mathrm{t}$ tabel atau $(5,787>2,011)$, dengan demikian hipotesis kedua yang diajukan bahwa terdapat pengaruh yang signifikan atara disiplin kerja terhadap kinerja pegawai diterima.

\section{Uji Hipotesis Simultan (Uji F)}

Pengujian hipotesis dengan uji $\mathrm{F}$ digunakan untuk mengetahui hipotesis simultan yang mana yang diterima.

Hipotesis ketiga Terdapat pengaruh yang signifikan antara gaya kepemimpinan dan disiplin kerja terhadap kinerja pegawai.

Tabel 13. Hasil Uji Hipotesis Gaya kepemimpinan dan Disiplin kerja Terhadap Kinerja Pegawai. ANOVA $^{a}$

\begin{tabular}{|c|c|c|c|c|c|c|}
\hline \multicolumn{2}{|c|}{ Model } & \multirow{2}{*}{$\begin{array}{l}\begin{array}{l}\text { Sum of } \\
\text { Squares }\end{array} \\
415816\end{array}$} & \multirow{2}{*}{$\frac{\mathrm{df}}{2}$} & \multirow{2}{*}{$\begin{array}{l}\begin{array}{l}\text { Mean } \\
\text { Square }\end{array} \\
207.908\end{array}$} & \multirow{2}{*}{$\frac{F}{39.385}$} & \multirow{2}{*}{$\frac{\text { Sig. }}{.000^{\mathrm{b}}}$} \\
\hline 1 & Regression & & & & & \\
\hline & Residual & 248.104 & 47 & 5.279 & & \\
\hline & Total & 663.920 & 49 & & & \\
\hline
\end{tabular}

a. Dependent Variable: Kinerja Pegawai (Y)

b. Predictors: (Constant), Disiplin Kerja (X2), Gaya kepemimpinan (X1)

Berdasarkan hasil pengujian pada tabel di atas, diperoleh nilai $\mathrm{F}$ hitung > F tabel atau $(39,385>2,800)$, dengan demikian hipotesis ketiga yang diajukan bahwa terdapat pengaruh yang signifikan atara gaya kepemimpinan dan disiplin kerja terhadap kinerja pegawai diterima.

\section{PEMBAHASAN HASIL PENELITIAN}

\section{Pengaruh Gaya kepemimpinan}

Terhadap Kinerja Pegawai

Gaya kepemimpinan berpengaruh signifikan terhadap kinerja pegawai dengan korelasi sebesar 0,737 atau memiliki hubungan yang kuat dengan kontribusi pengaruh sebesar 54,3\%. Pengujian hipotesis diperoleh nilai $t$ hitung $>\mathrm{t}$ tabel atau $(7,554>2,011)$. Dengan demikian hipotesis pertama yang diajukan bahwa terdapat berpengaruh signifikan antara gaya kepemimpinan terhadap kinerja pegawai diterima.

\section{Pengaruh Disiplin kerja Terhadap Kinerja Pegawai}

Disiplin kerja berpengaruh signifikan terhadap kinerja pegawai dengan korelasi sebesar 0,641 atau memiliki hubungan yang kuat dengan kontribusi pengaruh sebesar 41,1\%. Pengujian hipotesis diperoleh nilai $t$ hitung $>\mathrm{t}$ tabel atau $(5,787>2,011)$. Dengan demikian hipotesis kedua yang diajukan bahwa terdapat berpengaruh signifikan antara disiplin kerja terhadap kinerja pegawai diterima.

\section{Pengaruh Gaya Kepemimpinan dan Disiplin kerja Terhadap Kinerja Pegawai}

Gaya kepemimpinan dan disiplin kerja berpengaruh signifikan terhadap kinerja pegawai dengan diperoleh persamaan regresi $Y=7,707+0,463 X 1+$ 0,347X2, nilai korelasi sebesar 0,791 atau memiliki hubungan yang kuat dengan kontribusi pengaruh sebesar 62,6\% sedangkan sisanya sebesar 37,6\% dipengaruhi faktor lain. Pengujian hipotesis diperoleh nilai $\mathrm{F}$ hitung $>\mathrm{F}$ tabel atau $(39,385>2,800)$. Dengan demikian hipotesis ketiga yang diajukan bahwa terdapat berpengaruh signifikan antara gaya kepemimpinan dan disiplin kerja terhadap kinerja pegawai diterima. 


\section{PENUTUP}

\section{Kesimpulan}

1. Gaya kepemimpinan berpengaruh signifikan terhadap kinerja pegawai dengan kontribusi pengaruh sebesar $54,3 \%$. Uji hipotesis diperoleh nilai $\mathrm{t}$ hitung $>\mathrm{t}$ tabel atau $(7,554>2,011)$.

2. Disiplin kerja berpengaruh signifikan terhadap kinerja pegawai dengan kontribusi pengaruh sebesar $41,1 \%$. Uji hipotesis diperoleh nilai $\mathrm{t}$ hitung $>\mathrm{t}$ tabel atau $(5,787>2,011)$.

3. Gaya kepemimpinan dan disiplin kerja berpengaruh signifikan terhadap kinerja pegawai dengan kontribusi pengaruh sebesar $62,6 \%$ sedangkan sisanya sebesar $37,6 \%$ dipengaruhi faktor lain. Uji hipotesis diperoleh nilai $\mathrm{F}$ hitung $>\mathrm{F}$ tabel atau $(39,385>2,800)$.

\section{Saran}

1. Variabel Gaya kepemimpinan indikator yang paling lemah adalah indikator kharismatik. Untuk lebih baik lagi maka organisasi perlu mendorong pemimpin untuk lebih memiliki daya tarik yang kuat sehingga dapat menggerakkan bawahannya dalam melakukan pekerjaan.

2. Variabel Disiplin Kerja indikator yang paling lemah adalah indikator taat terhadap aturan waktu. Untuk lebih baik lagi maka organisasi perlu melakukan tindakan dengan memberikan sanksi atau hukuman agar para pegawai memiliki inisiatif untuk selalu datang dan pulang sesuai dengan waktu yang berlaku di organisasi.

3. Variabel Kinerja Pegawai indikator yang paling lemah adalah indikator kualitas kerja. Untuk lebih baik lagi maka organisasi perlu melakukan tindakan dengan memberikan bonus kepada pegawai yang dapat menyelesaikan pekerjaannya sesuai dengan target dan waktu yang telah ditentukan oleh organisasi.

4. Kontibusi pengaruh variabel bebas terhadap variabel terikat sebesar $62,6 \%$, nilai ini masih bisa ditingkatkan dengan secara selektif dapat memprioritaskan kinerja pegawai yang harus dipenuhi dan kondisi masing-masing variabel bebas harus ditingkatkan secara signifikan. Oleh karenanya disarankan kepada penelitian berikutnya agar melakukan penelitian yang relevan dengan cara memperbaiki indikator yang masih tidak baik atau dengan menambah indikator pertanyaan dan jumlah responden penelitian sehingga akan dapat lebih diketahui variabel yang paling memberikan kontribusi positif bagi organisasi.

\section{DAFTAR PUSTAKA}

Abdullah, M, "Manajemen dan Evaluasi Kinerja Karyawan", Penerbit Aswaja Pressindo, Yogyakarta, 2014.

Algifari, "Analisis Regresi", Yogyakarta, 2011.

Andi Supangat, "Statistika dalam Kajian Deskriptif, Inferensi dan Non Parametric", Edisi Pertama, Kencana Prenada Media Group, Jakarta, 2011.

Arikunto, Suharsimi, "Prosedur Penelitian Suatu Pendekatan Praktek", PT. Rineka Cipta, Jakarta, 2012.

Bejo Siswanto, "Manajemen Tenaga Kerja Rancangan dalam Pendayagunaan dan Pengembangan Unsur Tenaga Kerja", Sinar Baru, Bandung, 2010.

Dessler, Gary, "Manajemen Sumber Daya Manusia", Salemba Empat, Jakarta, 2015.

Effendy, Onong Uchjana, "Ilmu Komunikasi Teori dan Praktek", PT Remaja Rosdakarya, Bandung, 2013.

Gaol, CHR. Jimmy L, "A to Z Human Capital (Manajemen Sumber Daya Manusia) Konsep, Teori, dan Pengembangan dalam Konteks Organisasi Publik dan Bisnis", PT. Gramedia Widiasarana, Jakarta, 2014.

Ghozali, Imam, "Aplikasi Analisis Multivariate dengan Program SPSS", Edisi Kelima, Badan Penerbit Undip, Semarang, 2014.

Handoko, T. Hani, "Manajemen Personalia dan Sumber Daya Manusia. BPFEUGM, Yogyakarta, 2011.

Hariandja, Marihot T.E, “Manajemen 
Sumber Daya Manusia", Grasindo, Jakarta, 2013.

Hartatik, Indah Puji, "Mengembangkan SDM", Laksana, Yogyakarta, 2014.

Hasibuan, Malayu S.P, "Manajemen Sumber Daya Manusia", Edisi Revisi, PT Bumi Aksara, Jakarta, 2014.

Insani, P. B. E. B. (2020). Hubungan Gaya Kepemimpinan Dengan Produktivitas Kerja Pegawai Bmt El Bina Insani Cugenang. Jurnal Agrita Vol, 2(1).

Istijianto, "Aplikasi Praktis Riset Pemasaran", Gramedia Pustaka Utama, Jakarta, 2010.

Kartono, Kartini. "Pemimpin Dan Gaya kepemimpinan", Raja Grafindo Persada, Jakarta, 2014.

Kristianti, L. S., Affandi, A., Nurjaya, N., Sunarsi, D., \& Rozi, A. (2021). Pengaruh Motivasi Dan Disiplin Kerja Terhadap Kinerja Pegawai Pada Dinas Pariwisata Purwakarta. Jurnal Ilmiah PERKUSI, 1(1), 101-109.

Mangkunegara, Anwar Prabu AA. "Manajemen Sumber Daya Manusia Perusahaan", PT Remaja Rosdakarya, Bandung, 2013.

Marwansyah, "Manajemen Sumber Daya Manusia", PT. Alphabeta, Bandung, 2012.

Nurjaya, N., et al. (2021). The Effect of Product Promotion and Innovation Activities on Marketing Performance in Middle Small Micro Enterprises in Cianjur. Budapest International Research and Critics Institute (BIRCIJournal): Humanities and Social Sciences, 4(1), 528-540.

Paramarta, V., Dewi, R. R. V. K., Rahmanita, F., Hidayati, S., \& Sunarsi, D. (2021). Halal Tourism in Indonesia: Regional Regulation and Indonesian Ulama Council Perspective. International Journal of Criminology and Sociology, 10, 497-505.

Rivai V, Mulyadi D, "Gaya kepemimpinan dan Perilaku Organisasi", Rajawali pers, Jakarta,2011.
Samsudin, Sadili, "Manajemen Sumber Daya Manusia", CV. Pustaka Setia, Jakarta,2012.

Santoso, Singgih, "SPSS Statistik Parametik" Cetakan Kedua, PT. Elek Media, 2012.

Sedarmayanti, "Manajeme Sumber Daya Manusia Reformasi Birokras dan Manajemen Pegawai Negeri Sipil", PT. RefikaAditama, Bandung, 2013.

Setiyawan dan Waridin, "Pengaruh Disiplin Kerja dan Budaya Organisasi Terhadap Kinerja di Divisi Radiologi RSUP Dokter Kariadi", JRB, Semarang, 2012.

Siagian, Sondag, "Kiat Meningkatkan Produktivitas Kerja", PT. Rineka Cipta, Jakarta, 2012.

Silalahi, Ulber, "Asas-Asas Manajemen", Refika Aditama, Bandung, 2011.

Sinambela, Lijan Poltak, "Manajemen Sumber Daya Manusia: Membangun Tim Kerja Yang Solid Untuk Meningkatkan Kinerja", Bumi Aksara, Jakarta, 2016.

Sudjana, "Metode Statistika", Edisi Keenam, Tarsito, Bandung, 2011.

Sugiyono, "Metode Penelitian Kuantitatif Kualitatif dan R \& D", Penerbit CV. Alfabeta, Bandung, 2014.

Sutikno, Sobry M, "Pemimpin Dan Gaya kepemimpinan", Edisi Pertama, Holistica, Lombok, 2014.

Sutrisno, Edy, "Manajemen Sumber Daya Manusia", Kencana, Jakarta, 2016.

Terry, George dan Leslie W, Rue, "DasarDasar Manajemen", Cetakan kesebelas, PT. Bumi Aksara, Jakarta, 2010.

Thoha, Miftah, "Gaya kepemimpinan dalam Manajemen", PT. Raja Grafindo Persada, Jakarta,2013.

Wibowo, "Manajemen Kinerja", Edisi Ketiga, PT. Raja Grafindo Persada, Jakarta, 2011.

Zainal, V. Rivai, Mauliaman Darmansyah $\mathrm{H}$, dan Mansyur Ramly, "Gaya kepemimpinan dan Perilaku Organisasi", Edisi Keempat, PT Raja Grafindo Persada, Jakarta, 2014. 